\title{
Osteolytic Alteration, Cervical Myelopathy and Dysphonia Associated with Mucoepidermoid Carcinoma: A Case Report
}

\author{
Elbert Oberto Reyes Graterol Md, Ms, PHd ${ }^{1,2}$, Wilfredo Molina Wills DDs, Msc, Mshr, PHd ${ }^{3 *}$, Lorena Arditi Md ${ }^{4}$ \\ ${ }^{1}$ University of the Andes, Faculty of Medicine, Department of Morphological Sciences. Merida, Venezuela. \\ ${ }^{2}$ Servicio de Neurocirugía, Instituto Autónomo Hospital Universitario de Los Andes, Universidad de Los Andes, Mérida, Venezuela. \\ ${ }^{3}$ School of Medicine, Faculty of Medicine, Universidad de Los Andes, Mérida, Venezuela. \\ ${ }^{4}$ Resident of the fifth year of neurosurgery of the autonomous university institute of the Andes, Venezuela.
}

*Corresponding Author: Wilfredo Molina Wills, School of Medicine, Faculty of Medicine, Universidad de Los Andes, Mérida, Venezuela.

Received Date: 10 December 2021 | Accepted Date: 30 December 2021 | Published Date: 08 January 2022

Citation: E O R Graterol, Wilfredo M Wills, L Arditi. (2022). Osteolytic Alteration, Cervical Myelopathy and Dysphonia Associated with Mucoepidermoid Carcinoma: A Case Report. International Journal of Clinical Case Reports and Reviews. 10(2); DOI: 10.31579/2690-4861/196

Copyright: () 2022 Wilfredo Molina Wills, This is an open-access article distributed under the terms of the Creative Commons Attribution License, which permits unrestricted use, distribution, and reproduction in any medium, provided the original author and source are credited.

\begin{abstract}
:
Summary: A vertebral neoplasm of extraosseous origin, is that which affects the vertebra starting from a tissue that has metastized. Clinical diagnosis and imaging only provide an etiopatological approach due to various sources of metastasis, so early obtaining of material for sample analysis and timely treatment becomes important.

Objective: this study presents a 62-year-old male patient who manifested dysphonia, respiratory distress, cervical compressive myelopathy syndrome; being as a whole this picture with characteristics of increasing intensity and persistent imaging compatible with osteolysis of the spinous process of the fourth cervical vertebra.

Methods: lateral radiographs of preoperative cervical spine and cervical magnetic resonance without contrast in sequences $\mathrm{T} 1$ and T2 as well as cervical magnetic resonance without contrast axial cut sequence T2 were evaluated. A week after the diagnosis by image is taken to the operative table where resection of tumor mass associated with cervical paravertebral muscles, C4 laminectomy and exceresis of an extension of the tumor to the spinal canal (extradural) is performed and the anatomopathological study was performed.

Results: The patient presented improvement due to recovery of the respiratory bellows in the immediate post-operative period, although dysphonic persisted. The biopsy result reported mucoepidermoid carcinoma. We are interested in highlighting in this case the particular evolutionary association between the respiratory-laryngeal process, cervical osteolytic process and myelopathic manifestations as a regional development of the mucoepidermoid adenocarcinomatous neoplastic activity.
\end{abstract}

Keywords: mucoepidermoid carcinoma; myelopathy; osteolysis

\section{Introduction}

Spinal metastases represent a challenge, usually and because of the variety of tissues that originate the process. The current measures of care for patients with tumors have led to survival with the appropriate quality to our time. The spine represents a very common location of metastases to the bone [1], of which $10 \%$ have been reported related to the cervical spine [2]. Pain and neurological deficit continue to guide the physician in the syndromatic diagnosis although the difference in evolutionary success can be located in post-surgical therapeutics. Advances in radiotherapy as the treatment of choice for vertebral metastases, and chemotherapy have improved the quality of life of patients [3].
Spinal cord compression myelopathy is defined by invasion of the medullary canal by a tumor that advances locally or by a metastasis that produces compression or displacement of the spinal cord [4], and is classified into external and internal. According to the metastasis is located intramedullary or extramedullary [5], being the most frequent metastases, those with origin in the breast, lung and prostate [6].

\section{Clinical case}

Male patient of 62 years of age, who manifests onset of current disease of one month of evolution, characterized by progressive pain cervical of strong intensity, of sharp type, with irradiation to shoulders, calm partially with non-steroidal anti-inflammatory NSAIDs, concomitantly 
progressive decrease of the muscular strength of the four limbs, respiratory distress and dysphonic. He also manifested alterations for urination and constipation, which is why he is referred to the University Hospital of the Andes Mérida-Venezuela. During the physical evaluation, he was vigilant, conscious, oriented, fluent language with prolonged pauses, preserved memory. Norm photo reactive isochoric pupils, overall decrease in muscle strength (quadriparesis), muscle hypo tonicity, osteotendinous hyporeflexy, non-clonus, non-Babinsky and Dyspnea during rest.

\section{Images}

$\mathrm{X}$-ray of the cervical spine was performed in anteroposterior and lateral projections where rectification of the physiological curvature is observed, with the absence of a spinous process of C4 (Fig. 1). In simple Cervical Nuclear Magnetic Resonance in sagittal and axial cut, a rectification of physiological curvature was observed, an image of ovoid, extradural, poorly delimited shape, with irregular edges, of solid characteristics, with isointense behavior in sequence T1 (Fig. 2), hyperintensive in T2 sequence (Fig. 3, 4), which occupies the posterior portion of the spinal canal from $\mathrm{C} 3$ to $\mathrm{C} 4$, with muscle invasion, and involvement of laminae, spinous process of the vertebral bodies. C3-C4 extradural spinal space occupant injury is diagnosed. (Fig. 1) Lateral X-ray of the cervical spine preoperative. Rectification of the physiological curvature and absence of spinous process of $\mathrm{C} 4$ are observed. (Fig. 2) Cervical magnetic resonance without contrast $\mathrm{T} 1$ sequence is observed with isointense posterior cervical extradural spinal image.

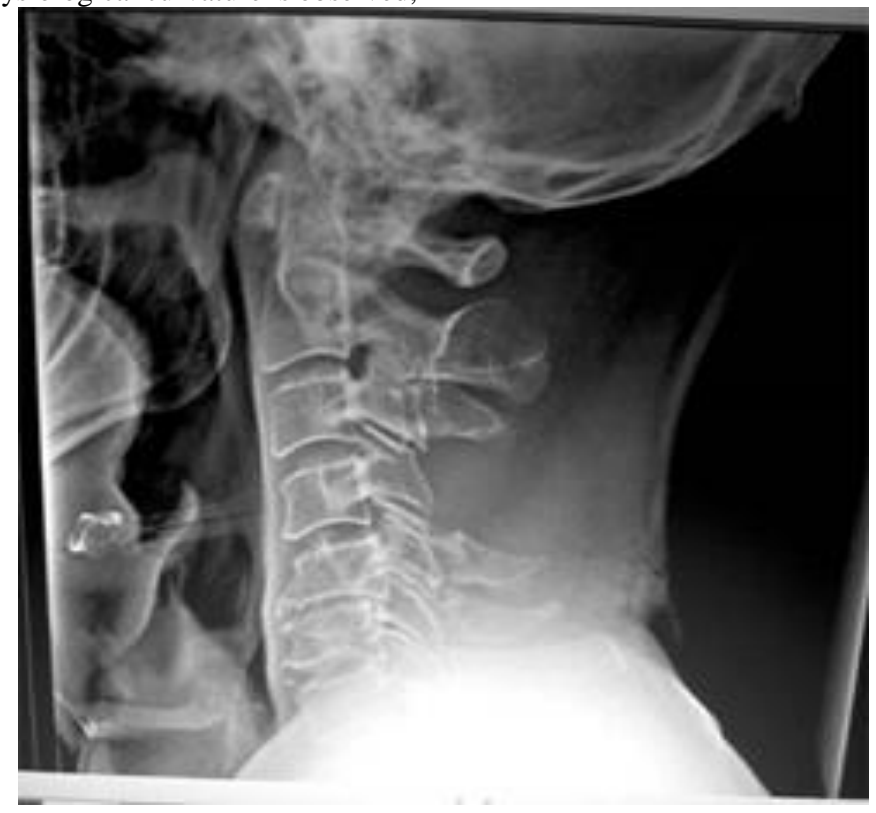

Figure 1: Lateral X-ray of the cervical spine preoperative Rectification of the physiological Curvature and absence of spinous process of C4 are observed.

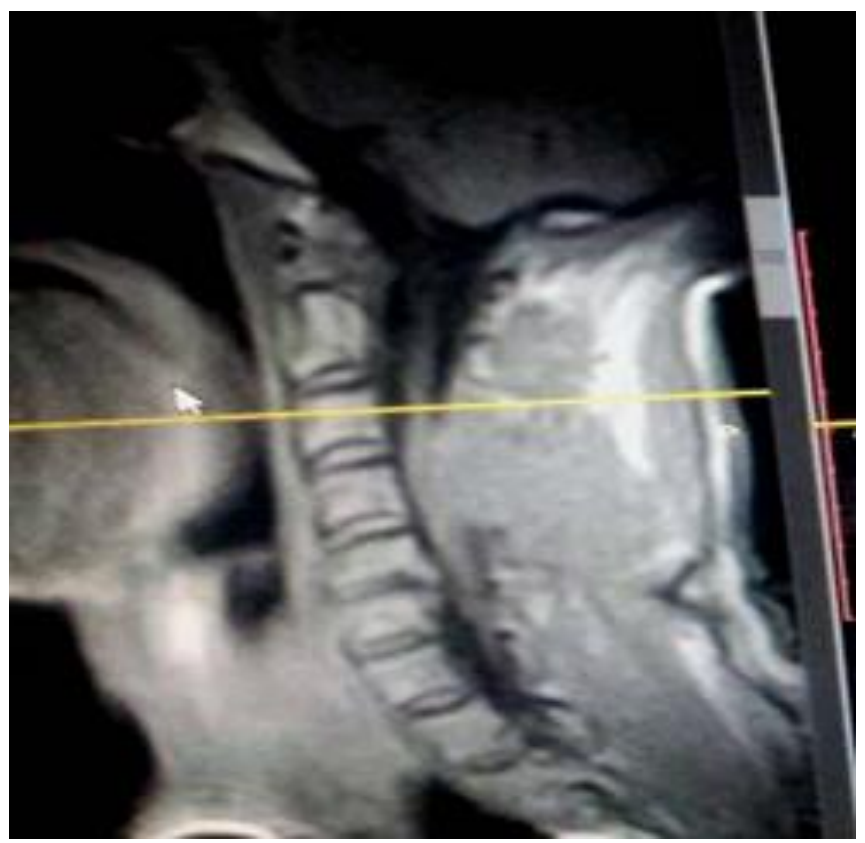

Figure 2: Cervical magnetic resonance without contrast T1 sequence is observed with Isointense posterior cervical extradural spinal Image. 


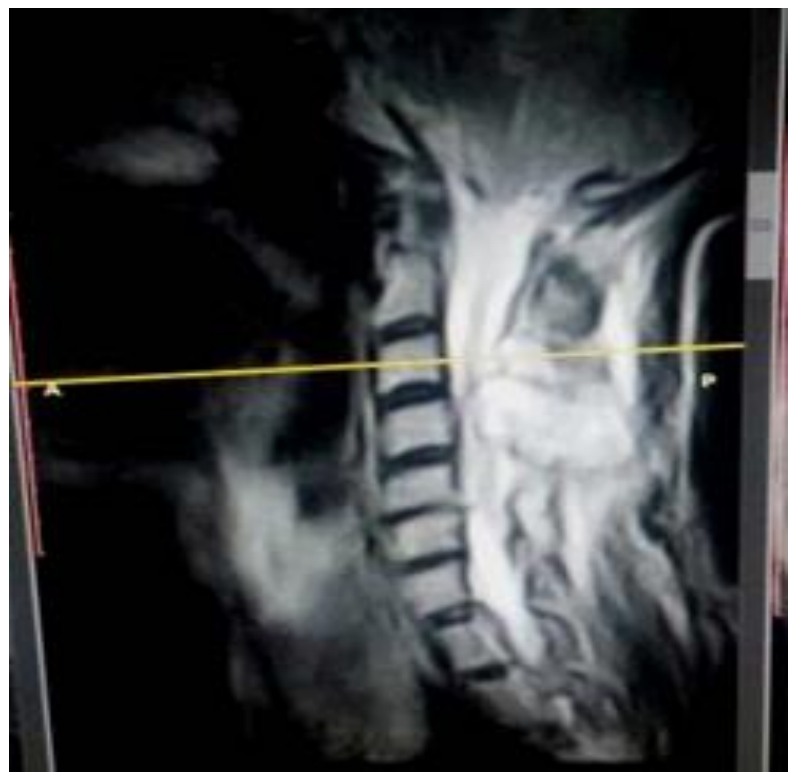

Figure 3: Cervical magnetic resonance without contrast $T 2$ sequence is observed with hyper intense posterior cervical extradural spinal image.

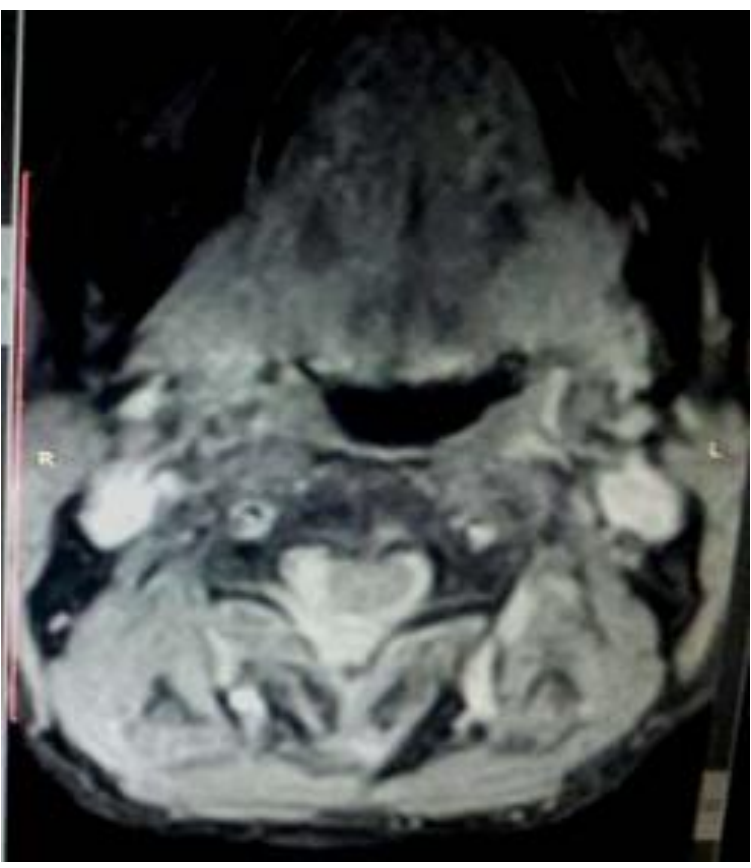

Figure 4: Cervical magnetic resonance without contrast, axial cut sequence T2.

\section{Surgical procedure}

Patient who is taken to the operating table one week after the imaging diagnosis. Where a cervical incision was made posterior from $\mathrm{C} 1$ to $\mathrm{C} 5$, dissection by planes. Among the findings, we observed a rounded mass attached to cervical paravertebral muscle of $3 \times 3 \times 3$ centimeters which we removed, with transformation of bone tissue to cartilaginous in c4 spinous process corroborated by histological study. Spinal decompression was then performed by $\mathrm{C} 3-\mathrm{C} 4$ laminectomy, extradural intraschid compressive mass exceresis.

Completed surgical act without complications, the patient had a satisfactory clinical evolution presenting improvement of the respiratory process.

\section{Anatomopathological Findings}

The histological sections of the examined material show malignant neoplasm of epithelial lineage consisting of cells with moderate to abundant amount of well-delimited cytoplasm, pleomorphic and hyper chromatic nuclei, others with chromatin in lumps, reinforcement of the nuclear membrane and evident nucleoli. Other cells show abundant welldelimited cytoplasm. These cells are arranged forming tubules, masses and nests that infiltrate the adjacent stroma. Cysts and areas with cribriform pattern with lights occupied by a cellular amorphous eosinophilic material are identified (Fig. 5, 6). 


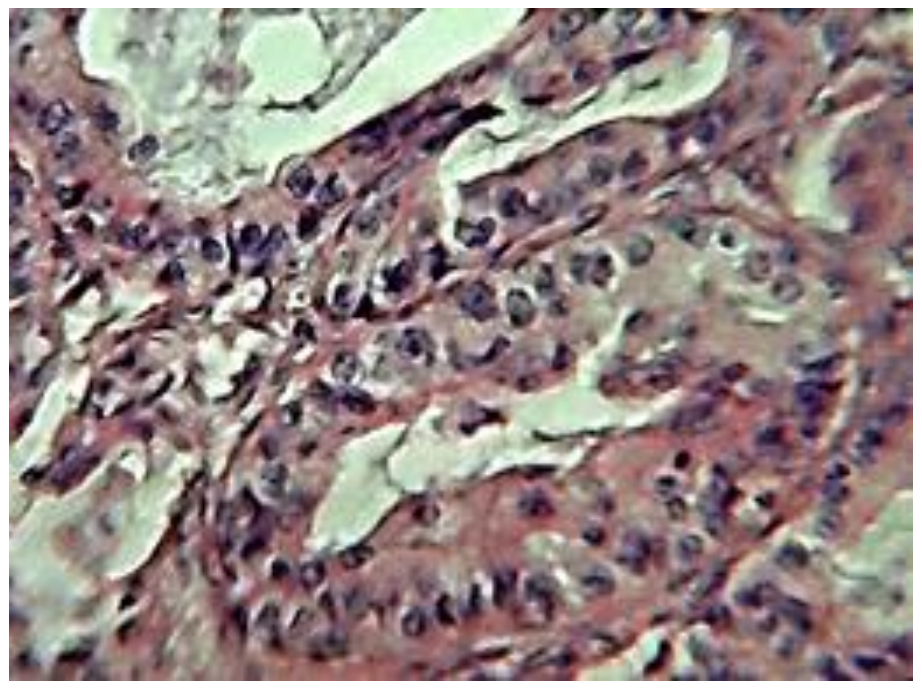

Figure 5: Histological cut with epithelial neoplastic infiltration.

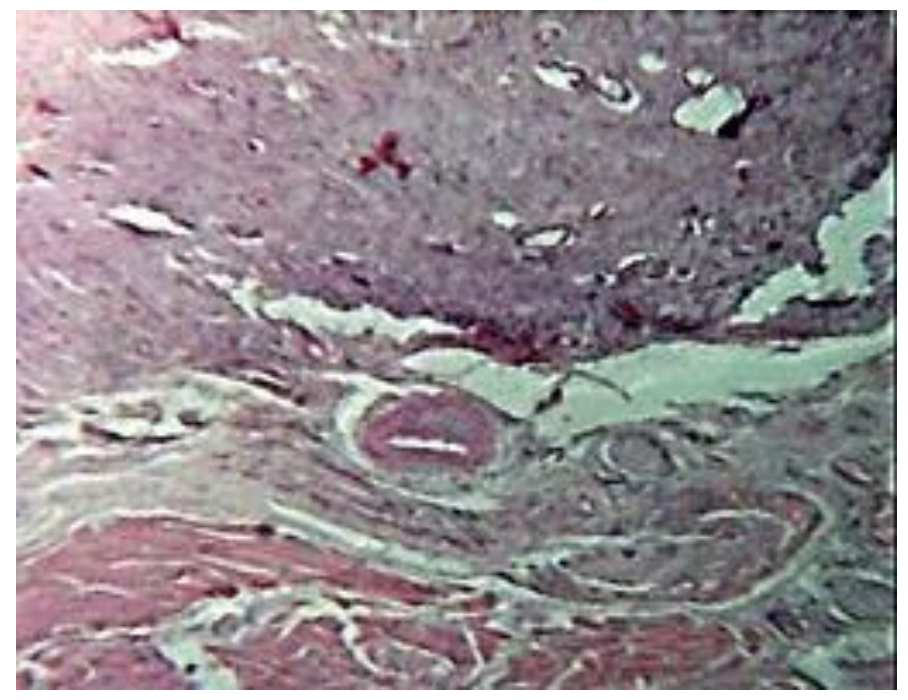

Figure 6: Histological cut with neoplastic infiltration of epithelial lineage, cells are arranged forming tubules.

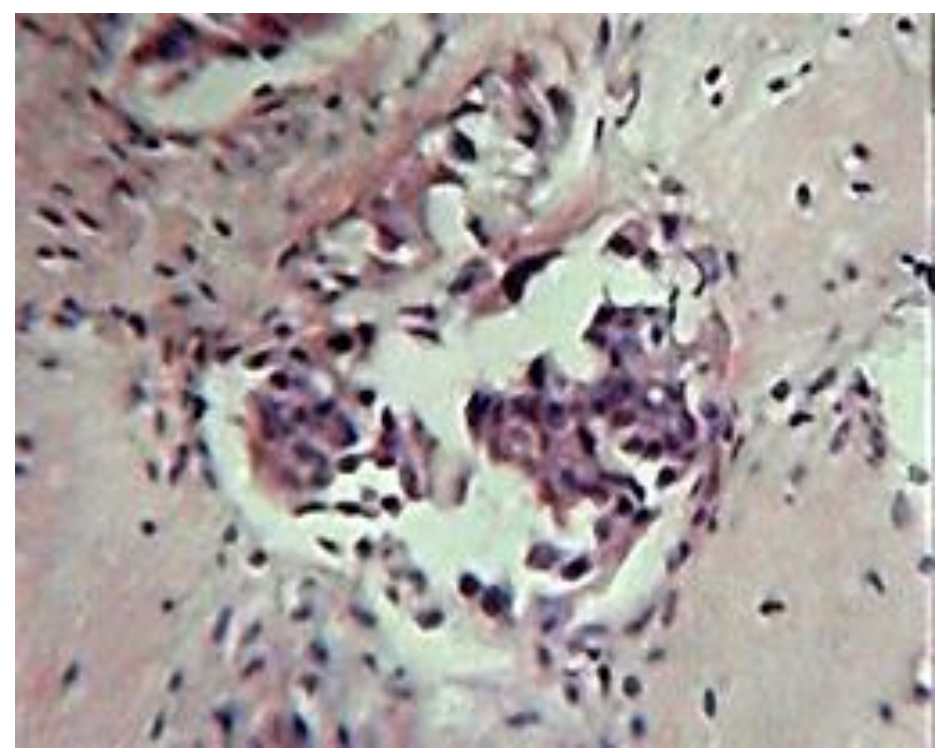

Figure 7: Histological cut bone tissue is observed, with infiltration of epithelial lineage, with muscle and cartilaginous tissue. 


\section{Discussion}

The spine is the third most frequent implantation site of systemic neoplasm metastases, then the lung and liver. Of the $40 \%$ of patients with spinal metastases, $10-20 \%$ developed medullary compression with myelopathic manifestations $[7,8]$.

In relation to age, there is a predilection as the primary origin of spinal metastases in adults, $50 \%$ of spinal metastases have their origin in the breast, lung and prostate (9), with metastases due to mucoepidermoid carcinoma rare in this location, with few reports in the literature, extradural localization metastases account for 95\% and intradural 5\%, topographically the location in the thoracic spine and dorsolumbar charnela constitutes $70 \%$, follows in frequency the lumbar spine and the sacrum in $20 \%$ and, being the least frequent location the cervical spine and the cervicothoracic charnela in $10 \%$. In the spinal axis, the spine is affected in $85 \%$ of cases, the paraspinal region in $10-15 \%$ and subarachnoid or intramedullary space in less than $5 \%$. In the vertebrae, the back of the body is affected first and then the anterior part of the body, the sheet and pedicles [9, 10].

The case presented of mucoepidermoid carcinoma in the spine as an extradural lesion, has an infrequent location according to the description of the reviewed literature, being the most common tumor of malignant tumors of salivary glands, and more frequent in the female sex between the third and sixth decade of life. Although, age coincides with epidemiological characteristics, although its clinical presentation presents with regional metastases mostly, with a minimum number of reports of invasion at a distance. The patient has no history of tumor lesions in salivary glands, nor pharyngeal or laryngeal lesions, debuting with a clinic of cervical pain, decreased muscle strength, respiratory distress, dysphonic and bone alterations at the imaging level, presenting useful characteristics for the early diagnosis and treatment of this type of injury.

\section{Ethical procedures}

All ethical procedures in this study were respected. The consents to carry out and the identity of the patient were taken into account according the Helsinki regulation.

\section{Conclusion}

Mucoepidermoid carcinoma at the cervical level is very rare, as well as its presentation. Imaging studies such as radiography, computed tomography and magnetic resonance imaging are very useful to make the diagnosis. The surgical treatment should have as its purpose the resection of the lesion in order to avoid complications and receive the treatment of chemotherapy and radiotherapy in the fastest way to avoid recurrence of the presented clinic.

\section{Conflict of interest}

None of the authors have conflicts of interest.

\section{References}

1. Bohm P, Huber J. (2002). The Surgical treatment of bony metastases of the spine and limbs. J Bone Joint Surg Br. 84(4):521-529.

2. Byrne T. (1992). Spinal cord compression from epidural metastases. N Engl J Med. 327(9):614-619.

3. Rev. (2006). venez. oncol. 18(3).

4. Helweg-Larsen S, Sorensen PS, Kreiner S. (2000). Prognostic factors in metastasic spinal cord compression: a prospective study using multivariate analysis of variables influencing survival and gait function in 153 patients. Int $\mathrm{J}$ Radiat Oncol Biol Phys. 46:1163-1169.

5. Jorcano P, Ibiza F, Vigara T. (2004). Diagnosticoy tratamiento de las metástasis vertebrales con compresión medular.Aten Primaria. 34(2):34:92-97.

6. The Princess Margaret Hospital. (2003). Experience of malignant spinal cord compression. Proc Am Soc Clin Oncol. 22.

7. Ruckdeschel JC. (2005). Early detection and treatment of spinal cord compression. Oncology (Willinston Park). 19:81-86.

8. Wong DA, Fornasier VI, McNabI. (1990). Spinal metastases: The obvius, the occult, and the impostors.Spine. 15:1-4.

9. Brihaye J, Ectors P, Lemort M, Van Houtte P. (1998). The Management of spinal epidural metastases. Advances and Technical Standards in Neurosurgery. 16:121-176.

10. Klimo P, Dailley AT,Fessler RG. (2004). Posterior surgical approaches and outcomes in metastatic spinal disease. Neurosurg Clin N Am. 15:425-435.

11. Bell D, El Naggar A. (2013). Molecular Hetrogeneity in Mucoepidermoid Carcinoma Conceptual and Practical implications.Head and NeckPathol. 7:23-27.

12. Kolude B, Lawoyin J, Akang E. (2001). Mucoepidermoid Carcinoma of the Oral Cavity. J Natl Med Assoc. 93:178-184.

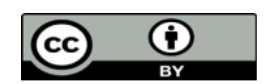

This work is licensed under Creative Commons Attribution 4.0 License
To Submit Your Article Click Here: $\quad$ Submit Manuscript

DOI: $10.31579 / 2690-4861 / 196$
Ready to submit your research? Choose Auctores and benefit from:

$>$ fast, convenient online submission

$>$ rigorous peer review by experienced research in your field

$>$ rapid publication on acceptance

$>$ authors retain copyrights

$>$ unique DOI for all articles

$>$ immediate, unrestricted online access

At Auctores, research is always in progress.

Learn more https://auctoresonline.org/journals/international-journal-of-clinicalcase-reports-and-reviews 